TITLE:

\title{
Analysis of anatomical and functional determinants of obstructive sleep apnea.
}

\section{$\operatorname{AUTHOR}(S)$ :}

Aihara, Kensaku; Oga, Toru; Harada, Yuka; Chihara, Yuichi; Handa, Tomohiro; Tanizawa, Kiminobu; Watanabe, Kizuku; ... Tsuboi, Tomomasa; Mishima, Michiaki; Chin, Kazuo

\section{CITATION:}

Aihara, Kensaku ...[et al]. Analysis of anatomical and functional

determinants of obstructive sleep apnea.. Sleep \& breathing 2012, 16(2): 473-481

\section{ISSUE DATE:}

2012-06

URL:

http://hdl.handle.net/2433/157356

\section{RIGHT:}

The final publication is available at www.springerlink.com; This is not the published version. Please cite only the published version.; この論文 は出版社版でありません。引用の際には出版社版をご確認ご利用くだ さい。 


\section{Analysis of anatomical and functional determinants of obstructive sleep apnea}

Kensaku Aihara $^{\mathrm{a}}, \mathrm{MD}$, Toru Oga ${ }^{\mathrm{b}}, \mathrm{MD}, \mathrm{PhD}$, Yuka Harada ${ }^{\mathrm{a}}, \mathrm{MD}$, Yuichi Chihara ${ }^{\mathrm{a}}, \mathrm{MD}$, Tomohiro Handa ${ }^{\mathrm{a}}, \mathrm{MD}, \mathrm{PhD}$, Kiminobu Tanizawa ${ }^{\mathrm{a}}, \mathrm{MD}$, Kizuku Watanabe ${ }^{\mathrm{a}}, \mathrm{MD}$, Takefumi Hitomi $^{\mathrm{b}}, \mathrm{MD}, \mathrm{PhD}$, Tomomasa Tsuboi ${ }^{\mathrm{b}}, \mathrm{MD}, \mathrm{PhD}$, Michiaki Mishima $^{\mathrm{a}}, \mathrm{MD}$, PhD, and Kazuo Chin ${ }^{\mathrm{b}}$, MD, PhD.

${ }^{a}$ Department of Respiratory Medicine, Graduate School of Medicine, Kyoto University, Kyoto, Japan.

${ }^{b}$ Department of Respiratory Care and Sleep Control Medicine, Graduate School of Medicine, Kyoto University, Kyoto, Japan.

Correspondence to: Toru Oga, MD, PhD.

Department of Respiratory Care and Sleep Control Medicine, Graduate School of Medicine, Kyoto University, 54 Kawahara, Shogoin, Sakyo-ku, Kyoto, 606-8507, Japan.

Tel: +81-75-751-3852Ｆax: +81-75-751-3854Ｅmail: ogato@kuhp.kyoto-u.ac.jp 


\section{Abstract}

Purpose: Craniofacial abnormalities have an important role in the occurrence of obstructive sleep apnea (OSA) and may be particularly significant in Asian patients, although obesity and functional abnormalities such as reduced lung volume and increased airway resistance also may be important. We conducted simultaneous analyses of their inter-relationships to evaluate the relative contributions of obesity, craniofacial structure, pulmonary function and airway resistance to the severity of Japanese OSA, because there are little data in this area.

Methods: A cross-sectional observational study was performed on 134 consecutive Japanese male patients. A sleep study, lateral cephalometry, pulmonary function tests and impulse oscillometry (IOS) were performed on all patients.

Results: Age, body mass index (BMI), position of the hyoid bone and proximal airway resistance on IOS (R20) were significantly related to the apnea/hypopnea index (AHI) $(p<0.05)$ in multiple regression analysis. Subgroup analysis showed that, for moderate-to-severe OSA (AHI $\geq 15$ events/hour), neck circumference and R20 were predominantly related to $\mathrm{AHI}$, whereas for non-to-mild OSA ( $\mathrm{AHI}<15$ events/hour), age and expiratory reserve volume were the predominant determinants. In obese subjects $\left(\mathrm{BMI} \geq 25 \mathrm{~kg} / \mathrm{m}^{2}\right)$, alveolar-arterial oxygen tension difference, position of the hyoid bone 
and R20 were significantly associated with AHI, whereas age alone was a significant factor in nonobese subjects $\left(\mathrm{BMI}<25 \mathrm{~kg} / \mathrm{m}^{2}\right)$.

Conclusions: As well as age and obesity, anatomical and functional abnormalities are significantly related to the severity of Japanese OSA. Predominant determinants of AHI differed depending on the severity of OSA or the magnitude of obesity.

Keywords: obstructive sleep apnea, obesity, cephalometry, pulmonary function, impulse oscillometry 


\section{Introduction}

Obstructive sleep apnea (OSA) is characterized by repetitive episodes of upper airway obstruction. The critical pathophysiological feature of OSA is sleep-related narrowing or closure of the upper airway at the level of the pharynx [1,2]. Anatomical abnormality is an important risk factor for OSA and most patients with OSA have craniofacial abnormalities such as a small mandible, enlarged tongue, enlarged soft palate, inferior displacement of the hyoid bone and imbalance between soft tissue volume and bony enclosure size [3-5]. Dempsey et al. [6] analyzed the interactive effects of obesity and craniofacial structure on sleep-disordered breathing (SDB), and reported that body mass index (BMI) and cephalometric dimensions equally contributed to the elevated apnea/hypopnea index (AHI). However, a recent study showed that craniofacial structure and obesity contributed differently to OSA between Caucasian and Asian patients [7]. In addition, Dempsey et al. pointed out some additional factors that might explain elevations in the $\mathrm{AHI}$ and speculated that functional abnormalities such as impaired neural control of upper airway muscles and ventilatory instability, which may cause increased airway resistance, might be candidates [6].

It has been shown that pharyngeal patency in OSA patients is lung volume-dependent $[8,9]$ and previous reports indicated a significant correlation between 
a reduced lung volume and nocturnal obstructive apnea and desaturation [10,11]. Increased upper airway resistance also was shown to play a role in the pathogenesis of OSA $[12,13]$ through the association with increased susceptibility of airway narrowing and collapse [2,14]. Thus, in addition to anatomical abnormalities, functional abnormalities such as reduced lung volume and increased airway resistance have been shown to play important roles in the pathogenesis of OSA.

Obesity, the most important risk factor for OSA, is known to affect craniofacial structures [15], lung volume [16] and airway resistance $[17,18]$. However, given the substantial number of nonobese OSA patients in Japan [19], we hypothesized that there would be significant relationships between OSA and anatomical and functional factors as well as obesity, reflecting a multi-factorial pathophysiological feature of OSA. Therefore, in the present study, we simultaneously analyzed the inter-relationships among craniofacial structure, pulmonary function, airway resistance, obesity and OSA to investigate the relative contributions of these factors to the severity of OSA.

\section{Materials and Methods}

\section{Study subjects}


We performed a cross-sectional observational study of 134 consecutive Japanese male patients who visited the Sleep Unit of Kyoto University Hospital between January 2009 and February 2010 for evaluation of OSA. None had been previously diagnosed with or treated for OSA. Patients with pulmonary diseases such as asthma or chronic obstructive pulmonary disease and who were diagnosed as having central sleep apnea were excluded. This study was approved by the Kyoto University Graduate School and Faculty of Medicine Ethics Committee and informed consent was obtained from all patients. A sleep study, lateral cephalometry, pulmonary function tests and impulse oscillometry (IOS) were performed on all patients. To establish smoking history, the Brinkman index was calculated by the following formula:

Brinkman index $=$ number of cigarettes smoked per day $\times$ number of smoking years Arterial blood gas analysis, including arterial partial pressure of oxygen $\left(\mathrm{PaO}_{2}\right)$ and arterial partial pressure of carbon dioxide $\left(\mathrm{PaCO}_{2}\right)$, was performed with patients' breathing room air at rest in the supine position at 19:00. Alveolar-arterial oxygen tension difference $\left(\mathrm{A}-\mathrm{aDO}_{2}\right)$ was calculated according to the standard formula, using the respiratory exchange ratio of 0.8 .

\section{Polysomnography}


Diagnosis of OSA was confirmed by polysomnography (SomnoStar pro, Cardinal Health, Dublin, OH, USA), which was started at 22:00 and ended at 6:00 the following morning. Surface electrodes were attached using standard techniques to obtain an electrooculogram, electromyogram of the chin, and 12-lead electroencephalograph. Sleep stages were defined according to the criteria of Rechtschaffen and Kales [20]. Ventilation was monitored by inductive plethysmography (Respitrace QDC, Viasys Healthcare, Palm Springs, CA, USA). Airflow was monitored by a nasal air pressure transducer (PTAFlite, Pro-Tech Services Inc., Mukilteo, WA, USA) and supplemented by an oronasal thermal sensor (Sleepmate Technologies, Midlothian, VA, USA). Arterial oxygen saturation $\left(\mathrm{SpO}_{2}\right)$ was monitored continuously with a pulse oximeter (Adult Flex System, Nonin Medical, Plymouth, MN, USA).

Apnea was defined as the complete cessation of airflow and hypopnea as a clear decrease in airflow of $30 \%$ or more lasting for 10 seconds or more, accompanied by a decrease in $\mathrm{SpO}_{2}$ of at least 4\% [21]. All AHI values were expressed as the number of episodes of apnea and hypopnea per hour over the total sleep time. The lowest $\mathrm{SpO}_{2}$ during sleep and the percentage of time of $\mathrm{SpO}_{2} 90 \%$ during sleep also were calculated in each patient. OSA severity was defined by the AHI as follows: non OSA $(\mathrm{AHI}<5)$, mild OSA $(5 \leq \mathrm{AHI}<15)$, moderate $\mathrm{OSA}(15 \leq \mathrm{AHI}<30)$ and severe $\mathrm{OSA}(\mathrm{AHI} \geq 30)$. 


\section{Cephalometry}

A lateral cephalogram was obtained for each subject. The cephalograms were taken on image plates (ST-VI, Fuji Medical Systems, Tokyo, Japan) with the subject in the sitting position at a film focus distance of $2 \mathrm{~m}$, with a left to right view. Exposures were made at $75 \mathrm{kV}$ and $320 \mathrm{~mA}$ at the end-expiratory phase during quiet breathing through the nose, and a cephalostat was used to keep the subject's head in a position such that the Frankfort horizontal line was parallel to the floor during exposure. Images of the cephalograms were digitized and input into a computer, previewed and processed for sharp visibility of both the soft tissues and bony structures and printed out through a computed radiography system (FCR Profect CS, Fuji Medical Systems). A total of 22 variables related to both craniofacial skeletal and soft tissue morphology were measured as angular (degrees), linear (millimeters) or area (square centimeters) by a single observer in a single-blind manner. Images were analyzed using Image $\mathbf{J}$ software (US, NIH, Bethesda, MD). Every measurement was made by the same observer, who had no knowledge of the clinical status of the patient.

The cephalometric landmarks and reference lines are defined in Table 1 and illustrated anatomically in Figure 1. The following angles and dimensions were 
measured: SNA, antero-posterior position of the maxilla in relation to the anterior cranial base (angle between S-N and N-A); SNB, antero-posterior position of the mandible in relation to the anterior cranial base (angle between S-N and N-B); ANB, relative position of the mandible to the maxilla (angle between $\mathrm{N}-\mathrm{A}$ and $\mathrm{N}-\mathrm{B}$ ); facial axis, vertical position of the mandible in relation to the skull (angle between Pt-Gn and $\mathrm{N}-\mathrm{Ba}$ ); G-VL, antero-posterior position of the chin in relation to the vertebra (linear distance along the perpendicular plane from $\mathrm{G}$ to $\mathrm{VL}$ ); $\mathrm{N}-\mathrm{Ba}$, the length of the cranial base (distance between $\mathrm{N}$ and $\mathrm{Ba}$ ); $\mathrm{S}-\mathrm{N}$, the length of the anterior cranial base (distance between $\mathrm{S}$ and N); ANS-PNS, the length of the hard palate (distance between ANS and PNS); PNS-Ba, bony nasopharynx (distance between PNS and Ba); PNS-P, the length of the soft palate (distance between PNS and P); PNS-V, the length of the pharyngeal airway (distance between PNS and V); MPT, greatest thickness of the soft palate; TGL, the length of the tongue (distance between V and TT); TGH, height of the tongue (linear distance along the perpendicular bisector of the V-TT line to the tongue dorsum); Me-Go, the length of the mandible (distance between Me and Go); MP-H, vertical position of the hyoid bone (linear distance along the perpendicular plane from $\mathrm{H}$ to MP); H-VL, antero-posterior position of the hyoid bone (linear distance along the perpendicular plane from $\mathrm{H}$ to $\mathrm{VL}$ ); AW1, upper oropharyngeal airway caliber 
(narrowest part of the airway between PNS and P); AW2, lower oropharyngeal airway caliber (narrowest part of the airway between P and Go); airway area, dimensions of the oropharynx (area outlined by the inferior border of the nasopharynx, the posterior surface of the soft palate and tongue, the line parallel to the palatal plate through the point $\mathrm{V}$, and the posterior pharyngeal wall); tongue area, dimensions of the tongue (area outlined by the dorsal aspect of the tongue surface and lines that join TT, G, H and V); and the lower face cage, the maxillomandibular enclosure size of the upper airway (cross-sectional area of the trapezoid enclosed by Cd-A-Pg-Cd'). Upper airway anatomical balance was assessed by the ratio between the tongue area and lower face cage as described in a previous study [5].

\section{Pulmonary function tests}

Pulmonary function tests were performed in the sitting position using CHESTAC (Chest M.I. Inc., Tokyo, Japan). Subjects underwent spirometric testing according to the recommended method [22]. Residual volume (RV) and total lung capacity (TLC) were measured by the closed-circuit helium method, and diffusing capacity for carbon monoxide $\left(\mathrm{DL}_{\mathrm{CO}}\right)$ was measured using a single-breath technique. 
The assessment of respiratory impedance was performed by IOS (Masterscreen IOS-J, Jaeger, Wurzburg, Germany). IOS is different from the classical forced oscillation technique (FOT) because an impulse rather than a pseudorandom noise signal is applied by the loudspeaker. Data processing is also different between IOS and FOT. But IOS yields respiratory system resistance and reactance values similar to those provided by FOT [23]. Subjects were measured first in the sitting position and then in the supine position, fulfilling standard recommendations [24], as previously reported in detail elsewhere $[25,26]$. In short, rectangular mechanical impulses containing the whole frequency spectrum were applied to the respiratory system through a mouthpiece while the patient was breathing quietly. The resulting pressure and flow signals were analyzed for amplitude, and the impedance $(Z)$ represents the total mechanical load of the subject's respiratory system from which the resistance $(\mathrm{R})$ and the reactance $(\mathrm{X})$ of the respiratory system can be derived. The frequency range of the signal was from 5 to $35 \mathrm{~Hz}$. The impedance at $5 \mathrm{~Hz}(\mathrm{Z} 5)$ represents the impedance of the total respiratory system. In the present study, we used respiratory resistance at 5 and $20 \mathrm{~Hz}$ (R5 and R20) as indices of total and proximal airway resistance, respectively. In IOS, low frequency oscillations are transmitted to the lung periphery, while those at frequencies $\geq 20 \mathrm{~Hz}$ are 
thought to be damped out before reaching the peripheral airways [27]. The reactance at $5 \mathrm{~Hz}$ (X5) may be determined by homogeneous distribution of ventilation, effective ventilation capacity, and compliance of the lung and chest wall. These indices have been shown to be useful for the evaluation of upper airway patency in OSA $[12,13]$.

\section{Statistics}

All statistical analyses were performed using StatView version 5.0 for Windows (Abacus Concepts, Berkeley, CA, USA). Continuous variables are expressed as means \pm standard deviation (SD). Intra-observer agreement for the cephalometric measurements was evaluated by the intraclass correlation coefficient (ICC) [28]. The natural logarithm of the AHI was used as the dependent variable since the absolute values were not distributed normally. Chi-square tests were used to compare dichotomous variables and unpaired Student's $t$ tests were used to compare continuous data between 2 groups. Relationships between 2 variables were analyzed by Pearson's correlation coefficient tests. Stepwise multiple regression analyses were performed to identify variables that could best explain AHI. A $p$ value less than 0.05 was considered to indicate statistical significance. 


\section{Results}

Relative contributions of obesity, craniofacial structure, pulmonary function and IOS measurements to $\mathrm{AHI}$ in all subjects

Patient characteristics and polysomnographic data are shown in Table 2. The study group of 134 patients comprised 19 non OSA, 32 mild OSA, 37 moderate OSA and 46 severe OSA patients. Regarding cephalometric measurements, intra-observer agreement was excellent (ICC ranged from 0.92 to 0.99 ) for all variables except for ANB and TGL, which had good intra-observer agreement $(\mathrm{ICC}=0.82$ in $\mathrm{ANB}$ and 0.83 in TGL). We investigated the associations between anthropometric variables, arterial blood gas data, cephalometric parameters, pulmonary function, IOS measurements and AHI. The AHI had a significant positive correlation with age $(r=0.26, p=0.003)$, BMI $(r=0.32, p=0.0002)$, neck circumference $(r=0.33, p=0.0001)$ and $\mathrm{A}_{-}-\mathrm{aDO}_{2}(r=0.37$, $p<0.0001)$ and a negative correlation with $\mathrm{PaO}_{2}(r=-0.31, p=0.0003)$ (Table E1). Examination of cephalometric parameters showed that the AHI had a significant positive correlation with the tongue area $(r=0.18, p=0.04)$, PNS-P $(r=0.30, p=0.0004)$, TGL $(r=0.23, p=0.008)$ and MP-H $(r=0.28, p=0.001)$ (Table E2). Regarding pulmonary function, there was a significant negative correlation between the AHI and only with the 
ERV (expiratory reserve volume) $(r=-0.28, p=0.001)$ and \%ERV $(r=-0.24, p=0.007)$

(Table E3). Results of IOS measurements revealed that the AHI had a significant positive correlation with R5 $(r=0.22, p=0.01)$ in the sitting position and Z5 $(r=0.19$, $p=0.03), \mathrm{R} 5(r=0.24, p=0.006)$ and $\mathrm{R} 20(r=0.25, p=0.004)$ in the supine position (Table E3).

Stepwise multiple regression analysis was performed to examine the relationships with AHI using the preselected variables that were significantly related to AHI in the above analyses (Table 3). Age, BMI, MP-H by cephalometry and R20 in the supine position on IOS significantly explained $28 \%$ of the variance in AHI $\left[r^{2}\right.$ (coefficient of determination) $=0.08,0.09,0.05$ and 0.06 , respectively] .

Relative contributions of obesity, craniofacial structure, pulmonary function and IOS measurements to the AHI based on the severity of OSA

We then compared the predominant determinants of AHI between 83 moderate-to-severe $(\mathrm{AHI} \geq 15)$ and 51 non-to-mild $(\mathrm{AHI}<15)$ OSA subjects. The clinical characteristics and polysomnographic data for these patients are shown in Table 4. The BMI and neck circumference were significantly higher and the $\mathrm{PaO}_{2}$ was significantly lower in moderate-to-severe OSA than in non-to-mild OSA $(p=0.007,0.002$ and 0.004 , 
respectively). As we did for the overall group of 134 patients, we performed stepwise multiple regression analyses to account for AHI in the moderate-to-severe and the non-to-mild groups, using the preselected variables that were significantly related to AHI. They included BMI, neck circumference, $\mathrm{PaO}_{2}, \mathrm{~A}-\mathrm{aDO}_{2}, \mathrm{R} 5$ and $\mathrm{R} 20$ in the sitting position, and Z5, R5 and R20 in the supine position in moderate-to-severe OSA and included age, $\mathrm{PaCO}_{2}, \mathrm{VC}, \mathrm{ERV}, \mathrm{FEV}_{1}, \mathrm{RV} / \mathrm{TLC}$ and $\% \mathrm{DL}_{\mathrm{CO}}$ in non-to-mild OSA. In moderate-to-severe OSA, neck circumference and R20 in the supine position on IOS $\left(r^{2}=0.11\right.$ and 0.10 , respectively) significantly explained $21 \%$ of the variance in AHI. By contrast, in non-to-mild OSA, age and ERV $\left(r^{2}=0.19\right.$ and 0.10 , respectively) significantly explained $29 \%$ of the variance in AHI.

Relative contributions of obesity, craniofacial structure, pulmonary function and IOS measurements to AHI based on the magnitude of obesity

We then compared the predominant determinants of AHI between 79 obese $(\mathrm{BMI} \geq 25)$ and 55 nonobese $(\mathrm{BMI}<25)$ subjects. The clinical characteristics and the polysomnographic data on these patients are shown in Table 5. There was a trend for more current smokers or ex-smokers to be present among the obese subjects. Neck circumference and the mean $\mathrm{AHI}$ were significantly higher and the $\mathrm{PaO}_{2}$ was 
significantly lower in obese subjects than in nonobese subjects $(p<0.0001, p=0.002$ and $p<0.0001$, respectively). We also performed stepwise multiple regression analyses to account for AHI in obese and nonobese subjects using the preselected variables that were significantly related to AHI. They included BMI, neck circumference, $\mathrm{PaO}_{2}$, A-aDO, PNS-P, TGL, MP-H, ERV, and R5 and R20 in the sitting and supine positions in obese subjects and age and $\mathrm{A}-\mathrm{aDO}_{2}$ in nonobese subjects. In obese subjects, $\mathrm{A}-\mathrm{aDO}_{2}$, MP-H by cephalometry and R20 in the sitting position on IOS $\left(r^{2}=0.08,0.10\right.$ and 0.07 , respectively) significantly accounted for $25 \%$ of the variance in AHI. In contrast, in nonobese subjects, age alone was significantly related to AHI $\left(r^{2}=0.25\right)$.

\section{Discussion}

We simultaneously analyzed the inter-relationships between OSA and obesity, anatomical abnormalities measured by cephalometry, and functional abnormalities measured by pulmonary function testing and IOS. By multiple regression analysis we found that age, BMI, MP-H by cephalometry and R20 on IOS significantly contributed to AHI. In addition, separate analyses revealed that significant determinants of OSA differed between moderate-to-severe OSA and non-to-mild OSA and between obese 
subjects and nonobese subjects.

In addition to age and obesity (BMI), an anatomical abnormality (inferior displacement of the hyoid bone) and a functional abnormality (increased proximal airway resistance) were significantly related to OSA. Obesity and age have been considered to be the characteristic risk factors for OSA [29]. On the other hand, certain forms of craniofacial abnormalities measured by cephalometry [3-5], reduced lung volume [8-11] and increased upper airway resistance [12,13] also have been suggested as predisposing factors for upper airway obstruction during sleep. Although these factors may be significantly affected by age and obesity [15-17,30,31], the relative contributions of anatomical and functional abnormalities, age and obesity to OSA have remained to be elucidated. Our findings indicate that OSA is the result of independent interrelationships among anatomical abnormalities, functional abnormalities, age and obesity, which reflects a multi-factorial pathophysiological feature of OSA.

We found that, compared with pulmonary function, airway resistance on IOS was related more closely to AHI. Structurally, the pharyngeal airway is surrounded by soft tissue, which is enclosed by bony structures and is caudally pulled by the thorax. As has been suggested, an imbalance between the amount of soft tissue and the size of the surrounding bony structures [32] and decreased thoracic traction [33] due to a reduced 
lung volume may result in increased tissue pressure surrounding the pharyngeal airway and decreased longitudinal tension of the pharyngeal airway wall, leading to increased upper airway resistance. Moreover, airway resistance was shown to increase when the body position changed from a sitting to a supine position [34]. In nonobese subjects, the falls in lung volume in a supine position are likely to lead to increased airway resistance, while in obese subjects in a supine position, such falls are smaller than in nonobese subjects and can only partly explain an increase in airway resistance [34]. Hence, there must be additional causes and sites of increased airway resistance in obese subjects. Our results showed the importance and usefulness of demonstrations of increased airway resistance on IOS in explaining the severity of OSA.

In one subgroup analysis, predominant determinants of AHI differed depending on the severity of OSA. In moderate-to-severe OSA, neck circumference and airway resistance were predominantly related to AHI, whereas in non-to-mild OSA, age and ERV were predominantly related to AHI. There was no overlap in those factors that were significantly associated with AHI, indicating a different pathogenesis of the disease between moderate-to-severe versus non-to-mild OSA. Asians were reported to have more severe OSA than Caucasians even when the BMI was similar between the two groups [7]. Our results indicate the importance of increased fat deposition adjacent 
to the upper airway rather than total body fat volume in Japanese individuals with moderate-to-severe OSA, which may partially explain this difference. Although it has been suggested that the consequences of craniofacial abnormalities are more severe in Japanese than in Caucasian OSA patients [3], craniofacial abnormalities were not significantly related to AHI in both moderate-to-severe and non-to-mild OSA groups in the present study after adjustment for other risk factors, although further study is needed. Moreover, that age independently correlated with non-to-mild OSA but not moderate-to-severe OSA may partly support the evidence that with increasing age OSA prevalence increases but that its severity does not $[19,29]$.

Another subgroup analysis showed that in obese subjects $\mathrm{A}-\mathrm{aDO}_{2}$, the distance between the hyoid bone and mandible, and airway resistance were predominantly related to AHI. A recent study suggested that subclinical lung injury may be present in OSA possibly through local oxidative stress in the alveolus [35,36]. Although the magnitude of the injury might not be great, given the effect of ventilation-perfusion inequality due to obesity [37], $\mathrm{A}-\mathrm{aDO}_{2}$ can be significantly related to $\mathrm{AHI}$ in obese OSA subjects. The position of the hyoid bone is correlated with accumulations of adipose tissue in pharyngeal regions, and its inferior displacement may give rise to the posterior relocation of the tongue and reduce upper airway patency $[3,38,39]$. Abdominal fat is 
likely to have direct effects on the downward movement of the diaphragm and is associated with increased airway resistance through the reduction in lung volume $[37,40]$. Our results may also imply the importance of abundant parapharyngeal and intraabdominal distribution of adipose tissue in obese subjects. Additionally, in nonobese subjects, age alone had a significant relationship with the AHI. The unexplained variance by age may be related to structural or functional abnormalities that were not measured, indicating the complicated pathogenesis of OSA in lean individuals.

Unfortunately, the four crucial features in our study account for only $28 \%$ of the variance in AHI. There are several possible explanations. Firstly, various determinants of OSA, not limited to obesity, might be characteristic in Japanese subjects. Secondly, all of our anatomical and functional measurements were obtained during wakefulness, which may have limited relevance to the sleeping state. Furthermore, some cephalometric measurements, including that of the position of the hyoid bone, may be affected by muscle contraction required for central occlusion of the jaw. Thirdly, we did not evaluate the degree of ventilatory control stability. It is termed "loop gain", whose increase is suggested to play an important role in the pathogenesis of OSA [41,42]. Additional assessments might have explained a certain proportion of the residual variance in AHI. 
As a limitation, the present study had a small sample size (especially non OSA subjects) with only male subjects from one university hospital, which might have limited the generalization of the results. Moreover, we only studied Japanese subjects and did not directly assess inter-ethnic differences in OSA risk factors. Considering that OSA is highly prevalent worldwide, inter-ethnic differences in OSA risk factors is an important issue. Although we discussed inter-ethnic differences by comparing the results with previous studies, such as those of a recent study by Lee et al. [7], further studies directly comparing OSA risk factors in different ethnic groups would more clearly elucidate those risk factors. Another limitation is that we assessed craniofacial structures only by cephalometry. Our limited measures of craniofacial morphology may underestimate the actual contributions of craniofacial morphology, especially of upper airway anatomical imbalance. Additional three-dimensional, volumetric evaluations using computed tomography [43] or magnetic resonance imaging [44] might show more sensitively the impact of anatomical imbalance on the pathogenesis of OSA.

OSA is a multi-factorial disease in which age and obesity play important roles. However, as well as age and obesity, our results indicated that both anatomical and functional abnormalities play significant roles in the pathogenesis of OSA. The severity of OSA or obesity appears to determine the relative contribution of these abnormalities 
to sleep-related collapse of the upper airway.

\section{Role of funding sources}

Kazuo Chin has received grants from the Japanese Ministry of Education, Culture, Sports, Science and Technology (nos. 20590921 and 22590760), Respiratory Failure Research Group and Health Science Research Grants (Comprehensive Research on Life-Style Related Diseases including Cardiovascular Diseases and Diabetes Mellitus) from the Ministry of Health, Labor and Welfare of Japan, and the Japan Vascular Disease Research Foundation. 


\section{References}

1 Hudgel DW (1992) Mechanisms of obstructive sleep apnea. Chest 101: 541-549.

2 Ryan CM, Bradley TD (2005) Pathogenesis of obstructive sleep apnea. J Appl Physiol 99: 2440-2450.

3 Sakakibara H, Tong M, Matsushita K, Hirata M, Konishi Y, Suetsugu S (1999) Cephalometric abnormalities in non-obese and obese patients with obstructive sleep apnoea. Eur Respir J 13: 403-410.

4 Yu X, Fujimoto K, Urushibata K, Matsuzawa Y, Kubo K (2003) Cephalometric analysis in obese and nonobese patients with obstructive sleep apnea syndrome. Chest 124: 212-218.

5 Tsuiki S, Isono S, Ishikawa T, Yamashiro Y, Tatsumi K, Nishino T (2008) Anatomical balance of the upper airway and obstructive sleep apnea. Anesthesiology 108: 1009-1015.

6 Dempsey JA, Skatrud JB, Jacques AJ, Ewanowski SJ, Woodson BT, Hanson PR, Goodman B (2002) Anatomic determinants of sleep-disordered breathing across the spectrum of clinical and nonclinical male subjects. Chest 122: 840-851.

7 Lee RW, Vasudavan S, Hui DS, Prvan T, Petocz P, Darendeliler MA, Cistulli PA (2010) Differences in craniofacial structures and obesity in Caucasian and Chinese patients with obstructive sleep apnea. Sleep 33: 1075-1080.

8 Heinzer RC, Stanchina ML, Malhotra A, Fogel RB, Patel SR, Jordan AS, Schory K, White DP (2005) Lung volume and continuous positive airway pressure requirements in obstructive sleep apnea. Am J Respir Crit Care Med 
172: 114-117.

9 Tagaito Y, Isono S, Remmers JE, Tanaka A, Nishino T (2007) Lung volume and collapsibility of the passive pharynx in patients with sleep-disordered breathing. J Appl Physiol 103: 1379-1385.

10 Bradley TD, Martinez D, Rutherford R, Lue F, Grossman RF, Moldofsky H, Zamel N, Phillipson EA (1985) Physiological determinants of nocturnal arterial oxygenation in patients with obstructive sleep apnea. J Appl Physiol 59: $1364-1368$.

11 Appelberg J, Nordahl G, Janson C (2000) Lung volume and its correlation to nocturnal apnoea and desaturation. Respir Med 94: 233-239.

12 Lin CC, Wu KM, Chou CS, Liaw SF (2004) Oral airway resistance during wakefulness in eucapnic and hypercapnic sleep apnea syndrome. Respir Physiol Neurobiol 139: 215-224.

13 Cao J, Que C, Wang G, He B (2009) Effect of posture on airway resistance in obstructive sleep apnea-hypopnea syndrome by means of impulse oscillation. Respiration 77: 38-43.

14 Dempsey JA, Veasey SC, Morgan BJ, O'Donnell CP (2010) Pathophysiology of sleep apnea. Physiol Rev 90: 47-112.

15 Mayer P, Pepin JL, Bettega G, Veale D, Ferretti G, Deschaux C, Levy P (1996) Relationship between body mass index, age and upper airway measurements in snorers and sleep apnoea patients. Eur Respir J 9: 1801-1809.

16 Salome CM, King GG, Berend N (2010) Physiology of obesity and effects on lung function. J Appl Physiol 108: 206-211.

17 Zerah F, Harf A, Perlemuter L, Lorino H, Lorino AM, Atlan G (1993) Effects 
of obesity on respiratory resistance. Chest 103: 1470-1476.

18 Watson RA, Pride NB (2005) Postural changes in lung volumes and respiratory resistance in subjects with obesity. J Appl Physiol 98: 512-517.

19 Ohdaira F, Nakamura K, Nakayama H, Satoh M, Ohdaira T, Nakamata M, Kohno M, Iwashima A, Onda A, Kobayashi Y, Fujimori K, Kiguchi T, Izumi S, Kobayashi T, Shinoda H, Takahashi S, Gejyo F, Yamamoto M (2007) Demographic characteristics of 3,659 Japanese patients with obstructive sleep apnea-hypopnea syndrome diagnosed by full polysomnography: associations with apnea-hypopnea index. Sleep Breath 11: 93-101.

20 Rechtschaffen A, Kales A (1968) A Manual of Standardized Terminology, Techniques and Scoring System for Sleep Stages of Human Subjects. Washington, DC: National Institutes of Health

21 Iber C, Ancoli-Israel S, Chesson A, Quan S (2007) The AASM Manual for the Scoring of Sleep and Associated Events: Rules, Terminology and Technical Specifications. American Academy of Sleep Medicine, Westchester, IL, USA

22 Miller MR, Hankinson J, Brusasco V, Burgos F, Casaburi R, Coates A, Crapo R, Enright P, van der Grinten CP, Gustafsson P, Jensen R, Johnson DC, MacIntyre N, McKay R, Navajas D, Pedersen OF, Pellegrino R, Viegi G, Wanger J (2005) Standardisation of spirometry. Eur Respir J 26: 319-338.

23 Hellinckx J, Cauberghs M, De Boeck K, Demedts M (2001) Evaluation of impulse oscillation system: comparison with forced oscillation technique and body plethysmography. Eur Respir J 18: 564-570.

24 Oostveen E, MacLeod D, Lorino H, Farre R, Hantos Z, Desager K, Marchal F (2003) The forced oscillation technique in clinical practice: methodology, 
recommendations and future developments. Eur Respir J 22: 1026-1041.

25 Takeda T, Oga T, Niimi A, Matsumoto H, Ito I, Yamaguchi M, Matsuoka H, Jinnai M, Otsuka K, Oguma T, Nakaji H, Chin K, Mishima M (2010) Relationship between small airway function and health status, dyspnea and disease control in asthma. Respiration 80: 120-126.

26 Haruna A, Oga T, Muro S, Ohara T, Sato S, Marumo S, Kinose D, Terada K, Nishioka M, Ogawa E, Hoshino Y, Hirai T, Chin K, Mishima M (2010) Relationship between peripheral airway function and patient-reported outcomes in COPD: a cross-sectional study. BMC Pulm Med 10: 10.

27 Goldman MD, Saadeh C, Ross D (2005) Clinical applications of forced oscillation to assess peripheral airway function. Respir Physiol Neurobiol 148: 179-194.

28 Bédard M, Martin NJ, Krueger P, Brazil K (2000) Assessing reproducibility of data obtained with instruments based on continuous measurements. Exp Aging Res 26: 353-365.

29 Young T, Shahar E, Nieto FJ, Redline S, Newman AB, Gottlieb DJ, Walsleben JA, Finn L, Enright P, Samet JM (2002) Predictors of sleep-disordered breathing in community-dwelling adults: the Sleep Heart Health Study. Arch Intern Med 162: 893-900.

30 Pecora NG, Baccetti T, McNamara JA Jr (2008) The aging craniofacial complex: a longitudinal cephalometric study from late adolescence to late adulthood. Am J Orthod Dentofacial Orthop 134: 496-505.

31 Janssens JP (2005) Aging of the respiratory system: impact on pulmonary function tests and adaptation to exertion. Clin Chest Med 26: 469-484. 
32 Watanabe T, Isono S, Tanaka A, Tanzawa H, Nishino T (2002) Contribution of body habitus and craniofacial characteristics to segmental closing pressures of the passive pharynx in patients with sleep-disordered breathing. Am J Respir Crit Care Med 165: 260-265.

33 Van de Graaff WB (1988) Thoracic influence on upper airway patency. J Appl Physiol 65: 2124-2131.

34 Michels A, Decoster K, Derde L, Vleurinck C, Van de Woestijne KP (1991) Influence of posture on lung volumes and impedance of respiratory system in healthy smokers and nonsmokers. J Appl Physiol 71: 294-299.

35 Lederer DJ, Jelic S, Basner RC, Ishizaka A, Bhattacharya J (2009) Circulating KL-6, a biomarker of lung injury, in obstructive sleep apnoea. Eur Respir J 33: 793-796.

36 Aihara K, Oga T, Harada Y, Chihara Y, Handa T, Tanizawa K, Watanabe K, Tsuboi T, Hitomi T, Mishima M, Chin K (2011) Comparison of biomarkers of subclinical lung injury in obstructive sleep apnea. Respir Med (in press)

37 Salome CM, King GG, Berend N (2010) Physiology of obesity and effects on lung function. J Appl Physiol 108: 206-211.

38 Guilleminault C, Riley R, Powell N (1984) Obstructive sleep apnea and cephalometric roentgenograms. Am Rev Respir Dis 130: 145-146.

39 Maltais F, Carrier G, Cormier Y, Series F (1991) Cephalometric measurements in snorers, non-snorers, and patients with sleep apnoea. Thorax 46: 419-423.

40 Begle RL, Badr S, Skatrud JB, Dempsey JA (1990) Effect of lung inflation on pulmonary resistance during NREM sleep. Am Rev Respir Dis 141: 854-860.

41 White DP (2005) Pathogenesis of obstructive and central sleep apnea. Am J 
Respir Crit Care Med 172: 1363-1370.

42 Verbraecken JA, De Backer WA (2009) Upper airway mechanics. Respiration 78: 121-133.

43 Shigeta Y, Ogawa T, Ando E, Clark GT, Enciso R (2011) Influence of tongue/mandible volume ratio on oropharyngeal airway in Japanese male patients with obstructive sleep apnea. Oral Surg Oral Med Oral Pathol Oral Radiol Endod 111: 239-243.

44 Saigusa H, Suzuki M, Higurashi N, Kodera K (2009) Three-dimensional morphological analyses of positional dependence in patients with obstructive sleep apnea syndrome. Anesthesiology 110: 885-890. 


\section{Figure Legends}

Figure 1.

Cephalometric landmarks and reference lines. For definitions, see Table 1. Shaded area indicates cross-sectional area of the tongue. Dark stained area indicates cross-sectional area of the airway. Lower face cage was defined as a trapezoid formed by Cd-A-Pog-Cd' (dotted lines). 
Figure 1.

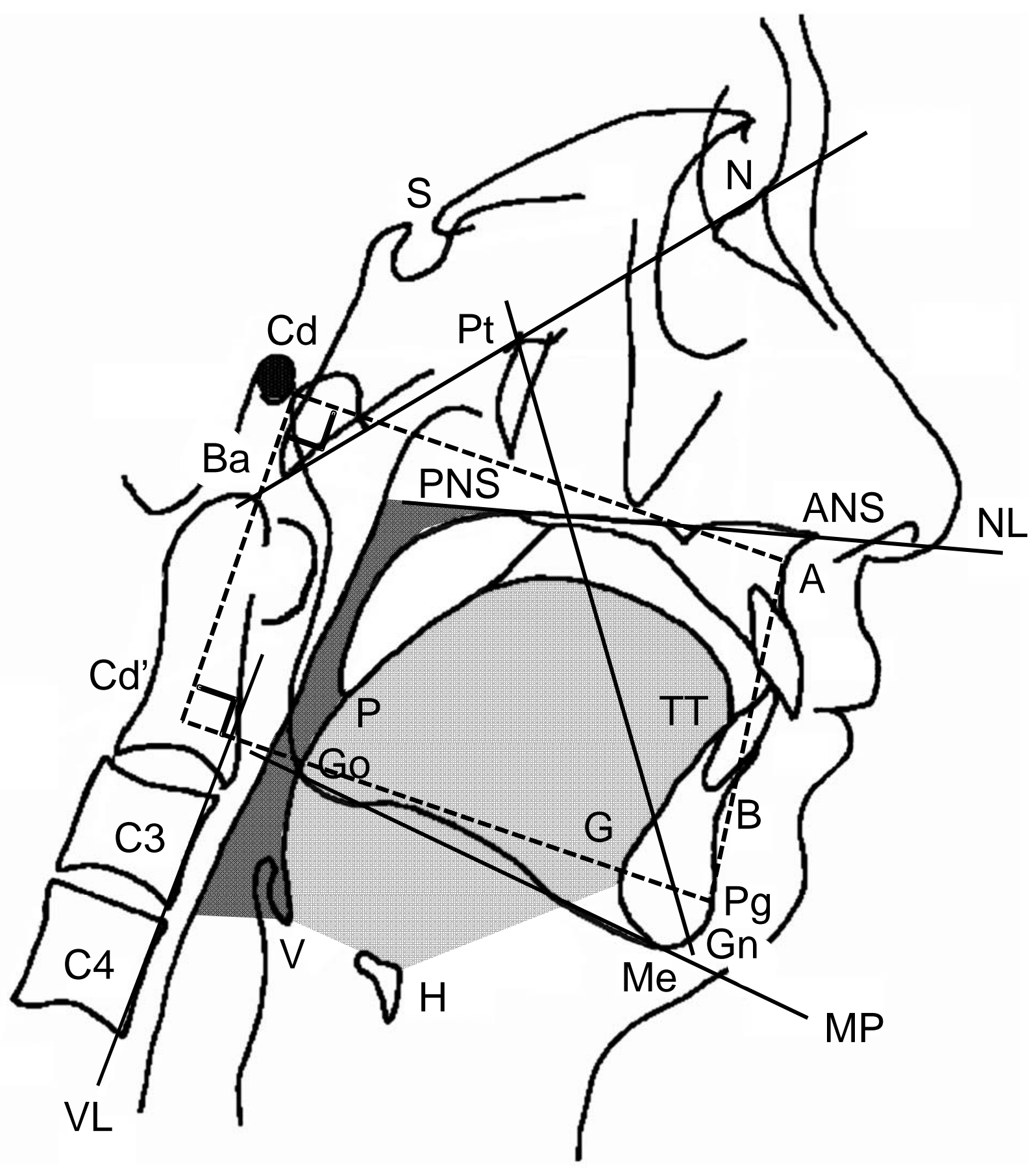


Table 1. Definitions of cephalometric landmarks and reference lines

S Sella, midpoint of the fossa hypophysealis

$\mathrm{N} \quad$ Nasion, anterior point at the frontonasal suture

ANS Anterior nasal spine, most anterior point of the nasal spine

PNS Posterior nasal spine, most posterior point of the nasal spine

A Deepest anterior point in the concavity of the anterior maxilla

B Deepest anterior point in the concavity of the anterior mandible

Cd Medial condylar point of the mandible

Cd'

A point that $\mathrm{Pg}$ projects onto the perpendicular line to the $\mathrm{Cd}-\mathrm{A}$ line at the $\mathrm{Cd}$ point

Go

Gonion, a mid-plane point at the gonial angle located by bisecting the posterior and inferior borders of the mandible

Me Menton, most inferior point of the chin bone

$\mathrm{Ba} \quad$ Basion, most posteroinferior point on the clivus

G Most posterior point on the symphysis of the mandible

$\mathrm{Pg}$ Prognathion, most anterior point on the symphysis of the mandible

$\mathrm{P} \quad$ Lowest point of the soft palate

TT Most anterior point of the tip of the tongue

$\mathrm{H} \quad$ Most anterosuperior point of the hyoid bone

V Most anteroinferior point of the epiglottic fold

$\mathrm{Pt}$ Intersection of the posterior pharyngeal wall and most inferior margin of the foramen rotundum

Gn Gnathion, the most antero-inferior point of body chin

NL Nasal line, a line through ANS and PNS

MP Mandibular plane, a plane constructed from Me through Go

VL A line across $\mathrm{C} 3$ and $\mathrm{C} 4$ 
Table 2. Clinical characteristics and polysomnographic data on 134 patients

\begin{tabular}{lc}
\hline Age (years) & $56.5 \pm 14.5$ \\
$\mathrm{BMI}\left(\mathrm{kg} / \mathrm{m}^{2}\right)$ & $26.5 \pm 4.2$ \\
Neck circumference $(\mathrm{cm})$ & $40.2 \pm 3.2$ \\
Smoking history (current/ex/never) & $37 / 70 / 27$ \\
Brinkman index & $528 \pm 603$ \\
$\mathrm{AHI}($ events/hour $)$ & $26.0 \pm 22.5$ \\
$\mathrm{Logarithmic} \mathrm{AHI}$ & $2.8 \pm 1.3$ \\
$\mathrm{Minimum} \mathrm{SpO}_{2}(\%)$ & $79.0 \pm 10.5$ \\
$\mathrm{SpO}_{2}<90 \%$ time/TST $(\%)$ & $14.8 \pm 21.4$ \\
$\mathrm{PaCO}_{2}(\mathrm{kPa})$ & $5.6 \pm 0.5$ \\
$\mathrm{PaO}_{2}(\mathrm{kPa})$ & $11.4 \pm 1.5$ \\
$\mathrm{~A}_{-\mathrm{aDO}}(\mathrm{kPa})$ & $1.6 \pm 1.5$ \\
\hline
\end{tabular}

Data presented as mean $\pm \mathrm{SD}$.

BMI: body mass index; AHI: apnea/hypopnea index; TST: total sleep time; $\mathrm{PaCO}_{2}$ : arterial partial pressure of carbon dioxide; $\mathrm{PaO}_{2}$ : arterial partial pressure of oxygen; $\mathrm{A}-\mathrm{aDO}_{2}$ : alveolar-arterial oxygen tension difference. 
Table 3. Stepwise multiple regression analysis to predict AHI (n=134)

\begin{tabular}{lc}
\hline & $r^{2}$ \\
\hline Age $($ years $)$ & 0.08 \\
$\mathrm{BMI}\left(\mathrm{kg} / \mathrm{m}^{2}\right)$ & 0.09 \\
$\mathrm{Neck}$ circumference $(\mathrm{cm})$ & - \\
$\mathrm{PaO}_{2}(\mathrm{kPa})$ & - \\
$\mathrm{A}-\mathrm{aDO}$ & $(\mathrm{kPa})$ \\
tongue area $\left(\mathrm{cm}^{2}\right)$ & - \\
$\mathrm{PNS}-\mathrm{P}(\mathrm{mm})$ & - \\
$\mathrm{TGL}(\mathrm{mm})$ & - \\
$\mathrm{MP}-\mathrm{H}(\mathrm{mm})$ & 0.05 \\
$\mathrm{ERV}(\mathrm{L})$ & - \\
$\% \mathrm{ERV}(\% \mathrm{pred})$ & - \\
$\mathrm{R} 5(\mathrm{kPa} / \mathrm{L} / \mathrm{sec})$ & - \\
$\mathrm{Z} 5^{*}(\mathrm{kPa} / \mathrm{L} / \mathrm{sec})$ & - \\
$\mathrm{R} 5{ }^{*}(\mathrm{kPa} / \mathrm{L} / \mathrm{sec})$ & 0.28 \\
$\mathrm{R} 2{ }^{*}(\mathrm{kPa} / \mathrm{L} / \mathrm{sec})$ & - \\
\hline $\mathrm{Cumulative}{ }^{2}$ & - \\
\hline
\end{tabular}

AHI: apnea/hypopnea index; $\mathrm{BMI}$ : body mass index; $\mathrm{PaO}_{2}$ : arterial partial pressure of oxygen; $\mathrm{A}-\mathrm{aDO}_{2}$ : alveolar-arterial oxygen tension difference; ERV: expiratory reserve volume.

* in the supine position. 
Table 4. Comparison of clinical characteristics and polysomnographic data between groups based on the severity of OSA

\begin{tabular}{lccc}
\hline & $\begin{array}{c}\mathrm{AHI} \geq 15 \\
(\mathrm{n}=83)\end{array}$ & $\begin{array}{c}\mathrm{AHI}<15 \\
(\mathrm{n}=51)\end{array}$ & $p$ value \\
\hline Age (years) & $57.6 \pm 12.3$ & $54.7 \pm 17.4$ & 0.26 \\
$\mathrm{BMI}\left(\mathrm{kg} / \mathrm{m}^{2}\right)$ & $27.2 \pm 4.6$ & $25.2 \pm 3.2$ & 0.007 \\
Neck circumference $(\mathrm{cm})$ & $40.9 \pm 3.5$ & $39.1 \pm 2.3$ & 0.002 \\
Smoking history (current/ex/never) & $18 / 46 / 19$ & $9 / 24 / 18$ & 0.18 \\
Brinkman index & $578 \pm 595$ & $446 \pm 613$ & 0.22 \\
$\mathrm{AHI}($ events/hour $)$ & $38.1 \pm 20.6$ & $6.5 \pm 4.4$ & $<0.0001$ \\
$\mathrm{Logarithmic} \mathrm{AHI}$ & $3.5 \pm 0.5$ & $1.5 \pm 1.2$ & $<0.0001$ \\
$\mathrm{Minimum} \mathrm{SpO}_{2}(\%)$ & $74.5 \pm 10.4$ & $86.3 \pm 5.0$ & $<0.0001$ \\
$\mathrm{SpO}_{2}<90 \%$ time/TST $(\%)$ & $22.9 \pm 23.7$ & $1.6 \pm 2.4$ & $<0.0001$ \\
$\mathrm{PaCO}_{2}(\mathrm{kPa})$ & $5.6 \pm 0.5$ & $5.7 \pm 0.4$ & 0.32 \\
$\mathrm{PaO}_{2}(\mathrm{kPa})$ & $11.1 \pm 1.4$ & $11.9 \pm 1.5$ & 0.004 \\
$\mathrm{~A}_{-\mathrm{aDO}}(\mathrm{kPa})$ & $1.9 \pm 1.4$ & $1.0 \pm 1.5$ & 0.0008 \\
\hline
\end{tabular}

Data presented as mean $\pm \mathrm{SD}$.

Unpaired $t$ tests were performed except for the chi-square test for smoking history.

BMI: body mass index; AHI: apnea/hypopnea index; TST: total sleep time; $\mathrm{PaCO}_{2}$ : arterial partial pressure of carbon dioxide; $\mathrm{PaO}_{2}$ : arterial partial pressure of oxygen; $\mathrm{A}-\mathrm{aDO}_{2}$ : alveolar-arterial oxygen tension difference. 
Table 5. Comparison of clinical characteristics and polysomnographic data between groups based on the magnitude of obesity

\begin{tabular}{lccc}
\hline & $\begin{array}{c}\mathrm{BMI} \geq 25 \\
(\mathrm{n}=79)\end{array}$ & $\begin{array}{c}\mathrm{BMI}<25 \\
(\mathrm{n}=55)\end{array}$ & $p$ value \\
\hline Age $($ years $)$ & $55.9 \pm 13.2$ & $57.3 \pm 16.3$ & 0.58 \\
$\mathrm{BMI}\left(\mathrm{kg} / \mathrm{m}^{2}\right)$ & $28.9 \pm 3.7$ & $22.9 \pm 1.4$ & $<0.0001$ \\
Neck circumference $(\mathrm{cm})$ & $41.7 \pm 3.0$ & $38.1 \pm 2.2$ & $<0.0001$ \\
Smoking history (current/ex/never) & $19 / 44 / 16$ & $8 / 26 / 21$ & 0.02 \\
$\mathrm{Brinkman}$ index & $611 \pm 618$ & $408 \pm 566$ & 0.054 \\
$\mathrm{AHI}($ events/hour $)$ & $31.0 \pm 25.6$ & $18.9 \pm 14.6$ & 0.002 \\
$\mathrm{Logarithmic} \mathrm{AHI}_{\mathrm{Minimum} \mathrm{SpO}}(\%)$ & $3.0 \pm 1.2$ & $2.5 \pm 1.3$ & 0.03 \\
$\mathrm{SaO}_{2}<90 \%$ time$/ \mathrm{TST}(\%)$ & $77.1 \pm 11.5$ & $81.8 \pm 8.2$ & 0.009 \\
$\mathrm{PaCO}_{2}(\mathrm{kPa})$ & $20.7 \pm 25.5$ & $6.3 \pm 8.2$ & $<0.0001$ \\
$\mathrm{PaO}_{2}(\mathrm{kPa})$ & $5.6 \pm 0.5$ & $5.6 \pm 0.4$ & 0.47 \\
$\mathrm{~A}_{-\mathrm{aDO}}(\mathrm{kPa})$ & $10.9 \pm 1.5$ & $12.0 \pm 1.4$ & $<0.0001$ \\
\hline
\end{tabular}

Data presented as mean $\pm \mathrm{SD}$.

Unpaired $t$ tests were performed except for the chi-square test for smoking history.

BMI: body mass index; AHI: apnea/hypopnea index; TST: total sleep time; $\mathrm{PaCO}_{2}$ : arterial partial pressure of carbon dioxide; $\mathrm{PaO}_{2}$ : arterial partial pressure of oxygen; $\mathrm{A}-\mathrm{aDO}_{2}$ : alveolar-arterial oxygen tension difference. 


\section{ELECTRONIC SUPPLEMENTARY MATERIAL}

\section{Sleep and Breathing}

Analysis of anatomical and functional determinants of obstructive sleep apnea

Kensaku Aihara ${ }^{\mathrm{a}}, \mathrm{MD}$, Toru Oga ${ }^{\mathrm{b}}, \mathrm{MD}, \mathrm{PhD}$, Yuka Harada ${ }^{\mathrm{a}}, \mathrm{MD}$, Yuichi Chihara ${ }^{\mathrm{a}}, \mathrm{MD}$, Tomohiro Handa ${ }^{\mathrm{a}}$, MD, PhD, Kiminobu Tanizawa ${ }^{\mathrm{a}}, \mathrm{MD}$, Kizuku Watanabe ${ }^{\mathrm{a}}, \mathrm{MD}$, Takefumi Hitomi ${ }^{\mathrm{b}}, \mathrm{MD}, \mathrm{PhD}$, Tomomasa Tsuboi ${ }^{\mathrm{b}}, \mathrm{MD}, \mathrm{PhD}$, Michiaki Mishima $^{\mathrm{a}}, \mathrm{MD}$, PhD, and Kazuo Chin ${ }^{\mathrm{b}}$, MD, PhD.

Correspondence to: Toru Oga, $\mathrm{MD}, \mathrm{PhD}$.

Department of Respiratory Care and Sleep Control Medicine, Graduate School of Medicine, Kyoto University, 54 Kawahara, Shogoin, Sakyo-ku, Kyoto, 606-8507, Japan.

Tel: +81-75-751-3852Ｆax: +81-75-751-3854Ｅmail: ogato@kuhp.kyoto-u.ac.jp 
Table E1. Relationships between clinical variables and AHI (n=134)

\begin{tabular}{|c|c|c|}
\hline & $r$ value & $p$ value \\
\hline Age (years) & 0.26 & 0.003 \\
\hline BMI $\left(\mathrm{kg} / \mathrm{m}^{2}\right)$ & 0.32 & 0.0002 \\
\hline Neck circumference $(\mathrm{cm})$ & 0.33 & 0.0001 \\
\hline Brinkman index & 0.14 & 0.11 \\
\hline $\mathrm{PaCO}_{2}(\mathrm{kPa})$ & -0.14 & 0.11 \\
\hline $\mathrm{PaO}_{2}(\mathrm{kPa})$ & -0.31 & 0.0003 \\
\hline $\mathrm{A}-\mathrm{aDO}_{2}(\mathrm{kPa})$ & 0.37 & $<0.0001$ \\
\hline
\end{tabular}

AHI: apnea/hypopnea index; $\mathrm{BMI}$ : body mass index; $\mathrm{PaCO}_{2}$ : arterial partial pressure of carbon dioxide; $\mathrm{PaO}_{2}$ : arterial partial pressure of oxygen; $\mathrm{A}-\mathrm{aDO}_{2}$ : alveolar-arterial oxygen tension difference. 
Table E2. Relationships between cephalometric parameters and AHI (n=134)

\begin{tabular}{|c|c|c|}
\hline & $r$ value & $p$ value \\
\hline airway area $\left(\mathrm{cm}^{2}\right)$ & -0.06 & 0.49 \\
\hline tongue area $\left(\mathrm{cm}^{2}\right)$ & 0.18 & 0.04 \\
\hline lower face cage $\left(\mathrm{cm}^{2}\right)$ & 0.01 & 0.95 \\
\hline tongue area/lower face cage $(\%)$ & 0.15 & 0.08 \\
\hline SNA $\left(^{\circ}\right)$ & -0.07 & 0.46 \\
\hline $\mathrm{SNB}\left(^{\circ}\right)$ & -0.11 & 0.23 \\
\hline $\operatorname{ANB}\left(^{\circ}\right)$ & 0.07 & 0.41 \\
\hline facial axis $\left(^{\circ}\right)$ & -0.04 & 0.67 \\
\hline AW1 (mm) & -0.11 & 0.22 \\
\hline AW2 (mm) & 0.00 & 0.96 \\
\hline G-VL (mm) & 0.06 & 0.46 \\
\hline $\mathrm{N}-\mathrm{Ba}(\mathrm{mm})$ & -0.01 & 0.89 \\
\hline S-N (mm) & -0.01 & 0.93 \\
\hline ANS-PNS (mm) & 0.01 & 0.89 \\
\hline PNS-Ba (mm) & -0.04 & 0.66 \\
\hline PNS-P (mm) & 0.30 & 0.0004 \\
\hline PNS-V (mm) & 0.11 & 0.22 \\
\hline MPT (mm) & 0.12 & 0.17 \\
\hline TGL (mm) & 0.23 & 0.008 \\
\hline TGH (mm) & -0.03 & 0.74 \\
\hline Me-Go (mm) & -0.05 & 0.55 \\
\hline MP-H (mm) & 0.28 & 0.001 \\
\hline H-VL (mm) & 0.11 & 0.21 \\
\hline
\end{tabular}

AHI: apnea/hypopnea index. 
Table E3. Relationships between pulmonary function, airway resistance and AHI $(\mathbf{n}=134)$

\begin{tabular}{|c|c|c|}
\hline & $r$ value & $p$ value \\
\hline $\mathrm{VC}(\mathrm{L})$ & -0.15 & 0.08 \\
\hline$\% \mathrm{VC}(\%$ pred $)$ & -0.07 & 0.44 \\
\hline $\operatorname{ERV}(\mathrm{L})$ & -0.28 & 0.001 \\
\hline$\%$ ERV (\% pred) & -0.24 & 0.007 \\
\hline $\mathrm{FEV}_{1}(\mathrm{~L})$ & -0.17 & 0.05 \\
\hline$\% \mathrm{FEV}_{1}(\%$ pred $)$ & 0.01 & 0.88 \\
\hline MMF (L/sec) & 0.00 & 0.98 \\
\hline$\% \mathrm{MMF}(\%$ pred $)$ & 0.11 & 0.20 \\
\hline$\%$ FRC (\% pred) & -0.10 & 0.27 \\
\hline \%RV (\% pred) & 0.06 & 0.52 \\
\hline$\%$ TLC (\% pred) & 0.07 & 0.46 \\
\hline RV/TLC (\%) & 0.10 & 0.27 \\
\hline$\% \mathrm{DL}_{\mathrm{CO}}(\%$ pred $)$ & -0.11 & 0.23 \\
\hline $\mathrm{Z} 5(\mathrm{kPa} / \mathrm{L} / \mathrm{sec})$ & 0.17 & 0.06 \\
\hline $\mathrm{R} 5(\mathrm{kPa} / \mathrm{L} / \mathrm{sec})$ & 0.22 & 0.01 \\
\hline $\mathrm{R} 20(\mathrm{kPa} / \mathrm{L} / \mathrm{sec})$ & 0.16 & 0.07 \\
\hline $\mathrm{X} 5(\mathrm{kPa} / \mathrm{L} / \mathrm{sec})$ & -0.09 & 0.29 \\
\hline $\mathrm{Z5}^{*}(\mathrm{kPa} / \mathrm{L} / \mathrm{sec})$ & 0.19 & 0.03 \\
\hline $\mathrm{R}^{*}(\mathrm{kPa} / \mathrm{L} / \mathrm{sec})$ & 0.24 & 0.006 \\
\hline $\mathrm{R} 20^{*}(\mathrm{kPa} / \mathrm{L} / \mathrm{sec})$ & 0.25 & 0.004 \\
\hline $\mathrm{X} 5^{*}(\mathrm{kPa} / \mathrm{L} / \mathrm{sec})$ & -0.13 & 0.14 \\
\hline
\end{tabular}

AHI: apnea/hypopnea index; VC: vital capacity; ERV: expiratory reserve volume; $\mathrm{FEV}_{1}$ : forced expiratory volume in 1 second; MMF: maximum mid-expiratory flow rate; FRC: functional residual capacity; RV: residual volume; TLC: total lung capacity; 
DLCO diffusing capacity for carbon monoxide.

* in the supine position. 